\title{
HUBUNGAN PEMBERIAN IMUNISASI DASAR DENGAN PERKEMBANGAN BAYI 9 DAN 12 BULAN DI POSKESDES DESA RENGAS I KEC. PAYARAMAN KAB. OGAN ILIR TAHUN 2019
}

\author{
Sri Rahayu \\ Program Studi DIII Akademi Kebidanan Pondok Pesantren Assanadiyah Palembang. \\ Jl. Banten 6. Kel.16 Ulu Kec.SU II Palembang \\ Email : riyadhnada93@gmail.com
}

\begin{abstract}
Abstrak
Imunisasi dasar sangat penting diberikan pada bayi berusia 0 - 12 bulan untuk memberikan kekebalan dari penyakit yang dapat dicegah dengan imunisasi (PD3I) antara lain Tuberkolosis, Difteri, Pertusis, Tetanus, Polio, Hepatitis B dan Campak. Pemberian imunisasi dasar sangat berpengaruh terhadap proses perkembangan bayi. Tujuan penelitian ini mengetahui Hubungan pemberian imunisasi dasar dengan perkembangan bayi. Penelitian ini dilakukan di Poskesdes Desa Rengas I Kec. Payaraman Kab. Ogan Ilir pada tanggal 15-17 April 2019. Populasi dalam penelitian ini berjumlah 22 responden, yang menjadi sampel dalam penelitian ini adalah seluruh jumlah dari populasi. Penelitian ini menggunakan metode survey analitik dengan teknik Total Sampling yang berjumlah 22 responden yang terdiri dari 16 responden (89\%) yang mendapat imunisasi dasar dan perkembangan tidak sesuai usia berjumlah 2 responden (11\%), sementara yang tidak mendapat imunisasi dasar lengkap dan perkembangan sesuai usia berjumlah 3 responden (75\%), yang tidak mendapat imunisasi dasar dan perkembangan tidak sesuai usia berjumlah 1 responden (25\%) Hasil penelitian pada kedua analisis tersebut menggunakan uji statistik chi-square didapatkan nilai $p_{-}$value $=(0,470)>\alpha(0,05)$ yang berarti tidak ada hubungan pemberian imunisasi dasar dengan perkembangan bayi usia 9 dan 12 bulan. Diharapkan bagi responden dapat menambah wawasan mengenai pemberian imunisasi dasar dengan perkembangan bayi tidak hanya berpatok dalam pelayanan kesehatan saja tetapi dari peran orang tua sendiri dalam memberikan kebutuhan bayi yang berupa Asah yaitu rangsangan atau latihan.
\end{abstract}

Kata kunci-Imunisasi Dasar, Perkembangan

\begin{abstract}
Basic immunization is very important given to infants aged 0-12 months to provide immunity from diseases that can be prevented by immunization (PD3I) including Tuberculosis, Diphtheria, Pertussis, Tetanus, Polio, Hepatitis $B$ and Measles. Provision of basic immunization is very influential on the process of developing the baby. The purpose of this study was to find out the relationship between basic immunization and infant development. This research was conducted at the Poskesdes Desa Rengas I Payaraman District. Ogan Ilir on April 15-17 2019. The population in this study amounted to 22 respondents, the sample in this study was the total population. This study used an analytical survey method with a total sampling technique which amounted to 22 respondents consisting of 16 respondents (89\%) who received basic immunization and development did not match the age of 2 respondents (11\%), while those who did not receive complete basic immunization and development accordingly age amounted to 3 respondents (75\%), who did not get basic immunization and development not according to age amounted to 1 respondent (25\%) The results of the study in both analyzes using the chi-square statistical test obtained the value of $p \_$value $=(0,470)>\alpha(0,05)$ which means there is no relationship between basic immunization and the development of infants aged 9 and 12 months. Suggestions are expected for respondents to add insight into the provision of basic immunization with the development of infants not only based on health services but from the role of parents themselves in providing baby needs in the form of Sharpening namely stimulation or training.
\end{abstract}

.Keywords—Basic Immunization, Development. 


\section{PENDAHULUAN}

Menurut data dari World Health Organization (WHO), prevalensi imunisasi pada anak secara global pada tahun 2012 ialah DPT sebesar $83 \%$, Polio sebesar $84 \%$, Campak sebesar 84\%, Hepatitis B sebesar $79 \%$, dan BCG sebesar $>80 \%$. Persentase imunisasi di dunia secara global terus meningkat dari tahun ketahun sebelumnya (WHO, 2012). Saat ini, imunisasi diperkirakan mencegah dua sampai tiga juta kematian setiap tahun di semua kelompok umur di dunia dari beberapa penyakit infeksi, diantaranya penyakit difteri, tetanus, pertusis, hepatitis $\mathrm{B}$, dan polio. Jumlah kematian pada anak di bawah lima tahun pada tahun 2008 adalah sebesar 8,8 juta anak, dengan sekitar $17 \%$ diantaranya merupakan kematian yang dapat dicegah dengan imunisasi. Sedangkan pada tahun 2011, jumlah kematian pada anak menurun menjadi 6,9 juta. Meskipun imunisasi terbukti dapat menurunkan angka morbiditas dan mortilitas pada anak, masih banyak anak di dunia yang belum mendapatkan perlindungan dengan imunisasi tersebut. Lebih dari $70 \%$ anak yang belum mendapatkan imunisasi tersebut bertempat tinggal di negara-negara berkembang seperti Ethiopia, India, Uganda, Afrika Selatan, Filipina dan Indonesia (WHO, 2012).

Imunisasi dasar sangat penting diberikan pada bayi berusia 0 - 12 bulan untuk memberikan kekebalan dari penyakit yang dapat dicegah dengan imunisasi (PD3I) antara lain Tuberkolosis, Difteri, Pertusis, Tetanus, Polio, Hepatitis B dan Campak (Depkes, 2005). Sementara itu, berdasarkan indikasi pencegahan penyakit, hak anak Indonesia untuk mendapatkan imunisasi juga masih belum sepenuhnya optimal. Berdasarkan data Kementerian Kesehatan, cakupan Universal Child Immunization (UCI) pada tahun 2010 adalah $75,3 \%$. Sedangkan pada tahun 2011 , pencapaian UCI turun menjadi $74,1 \%$ (Kemenkes, 2010).
Imunisasi adalah proses di mana seseorang dibuat kebal atau kebal terhadap penyakit menular, biasanya dengan pemberian vaksin. Vaksin merangsang sistem kekebalan tubuh sendiri untuk melindungi orang tersebut dari infeksi atau penyakit selanjutnya (WHO, 2015).

Imunisasi dasar adalah imunisasi pertama yang perlu diberikan pada semua orang, terutama bayi dan anak sejak lahir untuk melindungi tubuhnya dari penyakitpenyakit yang berbahaya (Anik, 2010).

Lima jenis imunisasi dasar yang diwajibkan pemerintah adalah imunisasi terhadap tujuh penyakit, yaitu TBC, difteri, tetanus, pertusis, (batuk rejan), poliomyelitis, campak dan hepatitis B.

Ada dua faktor yang mempengaruhi tumbuh kembang anak yaitu faktor genetik dan faktor lingkungan (milleu). Faktor lingkungan yang baik harus dapat menyediakan segala kebutuhan dasar anak untuk dapat tumbuh kembang optimal, yang kita kenal dengan asuh, asah dan asih. Asuh berupa kebutuhan fisis-biomedis, asah bermakna kebutuhan latihan/rangsangan/bermain/stimulasi, asih berarti kebutuhan akan kasih sayang/emosi (Titi Sularyo, 1994)

\section{METODE PENELITIAN}

Metode penelitian dengan survey analitik adalah survei atau penelitian yang mencoba menggali bagaimana dan mengapa fenomena kesehatan itu terjadi, survey penelitian memberikan perlakuan dengan observasi kepada bayi. Waktu pengumpulan data dengan Cross sectional Study atau penelitian dalam waktu singkat (Sugyono, 2017). Penelitian ini dengan tingkat eksplanasi Asosiatif untuk menjelaskan hubungan pemberian imunisasi dasar dengan perkembangan bayi usia 9 dan 12 bulan di Poskesdes Desa Rengas I Kec. Payaraman Kab. Ogan Ilir Tahun 2019. 


\section{Jenis Penelitian}

Penelitian ini dengan tingkat eksplanasi Asosiatif untuk menjelaskan hubungan pemberian imunisasi dasar dengan perkembangan bayi usia 9 dan 12 bulan di Poskesdes Desa Rengas I Kec. Payaraman Kab. Ogan Ilir Tahun 2019.

\section{Waktu dan Tempat Penelitian}

Penelitian ini dilakukan di Poskesdes Desa Rengas I Kec. Payaraman Kab. Ogan Ilir pada bulan 15 - 21 April Tahun 2019.

\section{Target/Subjek Penelitian}

Sampel dalam penelitian ini adalah bayi usia 9 dan 12 bulan poskesdes Poskesdes Desa Rengas I Kec. Payaraman Kab. Ogan Ilir tahun 2019 yang berjumlah 22 responden.

\section{Prosedur}

Melakukan izin penelitian ke Poskesdes Desa Rengas I Kec. Payaraman Kab. Ogan Ilir, Dalam penelitian ini pengumpulan data primer melalui wawancara dan checklist untuk data kelengkapan imunisasi dasar dan untuk memperoleh data perkembangan bayi 9 dan 12 bulan. Dalam penelitian ini pengumpulan data sekunder melalui data imunisasi lengkap dari bidan untuk data kelengkapan imunisasi dasar. setelah data selesai didapatkan data dimasukan data kedalam lembar Tabulasi dan Melakukan Pengolahan Data Collecting, Editing, Coding, Processing Cleaning dan Memasukkan Data yang Sudah ada ke Program SPSS IBM 22 Melakukan Analisa Data Analisa Univariat, Analisa Bivariat .

\section{Data, Intrumen, dan Teknik Pengumpulan Data}

Pengumpulan data pada penelitian ini adalah menggunakan data primer dan sekunder. Data primer adalah data yang diperoleh peneliti secara langsung dengan cara menggunakan wawancara dan checklis. Dalam penelitian ini pengumpulan data primer melalui wawancara dan checklist untuk data kelengkapan imunisasi dasar dan untuk memperoleh data perkembangan bayi 9 dan12 bulan. Data sekunder adalah data yang diperoleh peneliti dari sumber yang sudah ada. Dalam penelitian ini pengumpulan data sekunder melalui data imunisasi lengkap dari bidan yang untuk data kelengkapan imunisasi dasar.

Adapun instrument yang di gunakan oleh peneliti pada saat melakukan penelitian agar mendapat data yang relevan dengan menggunakan instrument pengumpulan data yaitu :

1. Checklist

Checklist ini digunakan untuk mengambil data imunisasi dasar lengkap dan menilai perkembangan pada bayi 9 dan 12 bulan.

2. Alat Tulis

Dan Teknik pengambilan sampel dalam penelitian ini dengan cara Total Sampling, yaitu teknik pengambilan sampel dimana jumlah sampel sama dengan populasi (Sugiyono, 2017).

\section{Teknik Analisa Data}

Analisa univariat merupakan analisa yang dilakukan untuk mengetahui data dalam bentuk tabel data di sajikan dalam bentuk tabel.:

Analisa bivariat dilakukan untuk melihat hubungan pemberian imunisasi dasar dengan perkembangan bayi usia 9 dan 12 bulan di Poskesdes Desa Rengas I Kec. Payaraman Kab. Ogan Ilir Tahun 2019, data diolah dengan menggunakanuji statistic Chi- Square dengan bantuan SPSS for windows, dengan tingkatan kemaknaan pada $95 \%(\alpha=0,05)$.

\section{HASIL PENELITIAN DAN PEMBAHASAN}

Analisa univariat merupakan analisa dilakukan untuk mengetahui data dalam bentuk tabel sebagai berikut :
a. Distribusi
Frekuensi Dan
Presentase Pemberian Imunisasi Dasar 
Tabel 1

Distribusi Frekuensi Dan Persentase

Pemberian Imunisasi Dasar Pada Bayi Usia 9 Dan 12 Bulan Di Poskesdes Desa Rengas I Kec. Payaraman Kab. Ogan Ilir Tahun 2019

\begin{tabular}{clcc}
\hline No. & Imunisasi & f & $\mathbf{( \% )}$ \\
\hline 1. & Lengkap & 18 & 81,8 \\
\hline 2. & Tidak Lengkap & 4 & 18,2 \\
\hline & Total & $\mathbf{2 2}$ & $\mathbf{1 0 0 , 0}$ \\
\hline
\end{tabular}

Dari tabel 1 di atas dapat dilihat bahwa data responden yang mendapat imunisasi dasar lengkap sebanyak 18 responden $(81,8 \%)$, dan yang imunisasi dasar tidak lengkap sebanyak 4 responden $(18,2 \%)$.

b. Distribusi Frekuensi Dan Presentase Perkembangan Bayi Usia 9 dan 12 Bulan

Tabel 2

Distribusi Frekuensi Dan Presentase Perkembangan Bayi Usia 9 Dan 12 Bulan Di Poskesdes Desa Rengas Kec. Payaraman Kab. Ogan Ilir Tahun 2019

\begin{tabular}{llll}
\hline No. & Perkembangan & $\mathbf{f}$ & $\mathbf{( \% )}$ \\
\hline 1. & Sesuai Usia & 19 & 86,4 \\
\hline 2. & Tidak Sesuai Usia & 3 & 13,6 \\
\hline & Total & $\mathbf{2 2}$ & $\mathbf{1 0 0 , 0}$ \\
\hline
\end{tabular}

Dari tabel 2 di atas dapat dilihat bahwa data responden yang perkembangan sesuai usia sebanyak 19 responden $(86,4 \%)$,dan yang perkembangan tidak sesuai usia sebanyak 3 responden $(13,6 \%)$.

Analisa bivariat dilakukan untuk melihat hubungan perkembangan bayi yang mendapat imunisasi dasar lengkap dan yang tidak mendapat imunisasi dasar lengkap. Data diolah dengan uji statistic Chi-square dengan bantuan SPSS for Windows.
Tabel 3

Hubungan pemberian imunisasi dasar Dengan Perkembangan Bayi Usia 9 Dan 12Bulan di Poskesdes Desa Rengas I Kec. PayaramanKab. Ogan Ilir Tahun 2019

\begin{tabular}{|c|c|c|c|c|c|c|c|c|}
\hline \multirow{3}{*}{ No. } & \multirow{3}{*}{ Imunisasi } & \multicolumn{4}{|c|}{ Perkembangan } & \multirow{2}{*}{\multicolumn{2}{|c|}{ Total }} & \multirow{3}{*}{$\begin{array}{l}\text { p_val } \\
\text { ue }\end{array}$} \\
\hline & & \multicolumn{2}{|c|}{$\begin{array}{l}\text { Sesuai } \\
\text { Usia }\end{array}$} & \multicolumn{2}{|c|}{$\begin{array}{l}\text { Tidak } \\
\text { Sesuai } \\
\text { Usia }\end{array}$} & & & \\
\hline & & $\mathbf{F}$ & $(\%)$ & $\mathbf{f}$ & $(\%)$ & f & $\begin{array}{l}(\% \\
1 \%\end{array}$ & \\
\hline 1. & $\begin{array}{l}\text { Imunisasi } \\
\text { Dasar } \\
\text { Lengkap }\end{array}$ & 16 & 88,9 & 2 & 11,1 & 18 & $\begin{array}{l}10 \\
0,0\end{array}$ & \\
\hline 2. & $\begin{array}{l}\text { Imunisasi } \\
\text { Dasar Tidak } \\
\text { Lengkap } \\
\text { atau tidak } \\
\text { imunisasi }\end{array}$ & 3 & 75,0 & 1 & 25,0 & 4 & $\begin{array}{l}10 \\
0,0\end{array}$ & $\mathbf{0 , 4 7 0}$ \\
\hline To & & 19 & 86,4 & 3 & 13,6 & 22 & $\begin{array}{l}10 \\
0,0\end{array}$ & \\
\hline
\end{tabular}

Berdasarkan data tabel 3 di atas menujukkan bahwa dari22 responden yang mendapat imunisasi dasar lengkap dan perkembangan sesuai usia berjumlah 16 responden $(88,9 \%)$, yang mendapat imunisasi dasar lengkap dan perkembangan tidak sesuai usia berjumlah 2 responden $(11,1 \%)$, sementara yang imunisasi dasar tidak lengkap dan perkembangan sesuai usia berjumlah 3 responden $(75,0 \%)$, yang tidak mendapat imunisasi dasar dan perkembangan tidak sesuai usia berjumlah 1 responden $(25,0 \%)$. Setelah dilakukan uji statistik chi-square hasil p_value $=(0,470)$ $>\alpha(0,05)$ yang berarti tidak ada hubungan bermakna antara Pemberian Imunisasi Dasar Dengan Perkembangan Bayi Usia 9 Dan 12 Bulan, dengan demikian hipotesis yang menyatakan ada hubungan Pemberian Imunisasi Dasar Dengan Perkembangan Bayi Usia 9 Dan 12 Bulan tidak terbukti secara statistik. 


\section{KESIMPULAN}

Setelah dilakukan uji statistik chi-square hasil p_value $=(0,470)>\alpha(0,05)$ yang berarti tidak ada hubungan bermakna antara Pemberian Imunisasi Dasar Dengan Perkembangan Bayi Usia 9 Dan 12 Bulan, dengan demikian hipotesis yang menyatakan ada hubungan Pemberian Imunisasi Dasar Dengan Perkembangan Bayi Usia 9 Dan 12 Bulan tidak terbukti secara statistik. Walaupun dari hasil statistik menujukkan tidak ada hubungan bermakna antara pemberian imuninasi dasar dengan perkembangan bayi usia 9 dan 12 bulan, tetapi dilihat dari nilai OR sebesar 2,667, hal tersebut menunjukkan bahwa bayi yang tidak mendapatkan imunisasi dasar lengkap mempunyai peluang 2,667 kali untuk perkembangan sesuai dengan usia.

Kebutuhan fisis-biomedis atau asuh mencakup kebutuhan nutrisi yang seimbang dan tepat, perawatan kesehatan dasar, pakaian, perumahan, higiene diri dan lingkungan serta kesegaran jasmani. Perawatan kesehatan dasar, yang termasuk di dalamnya adalah imunisasi dan usaha pencegahan morbiditas pada anak yang lainnya. Anak yang sehat akan tumbuh dan berkembang dengan baik, sedangkan anak yang sering sakit akan terganggu pula tumbuh kembangnya.

Menurut Yuniarti (2015), aspek perkembangan mencakup aspek kognitif, aspek fisik, aspek bahasa, sosio-emosional, moral dan spiritual. Meskipun pemberian imunisasi tidak lengkap namun perkembangan tidak hanya berpatokan dalam satu hal saja karena pola perkembangan berlangsung dalam beberapa tahap. Dan peran orang tua sangat dibutuhkan dalam tahap perkembangan anak seperti teori Menurut Perry Potter (2005) bahwa faktor yang mempengarui perkembangan salah satunya adalah stimulasi (Rangsangan/latihan), yaitu ketersediaan sarana untuk tumbuh kembang anak maupun peran serta orang tua atau orang disekitarnya untuk membantu proses tumbuh kembang.

\section{SARAN}

Hasil penelitian ini diharapkan menambah wawasan dan pengetahuan dalam penelitian dan dapat dikembangkan lagi penelitianpenelitian sejenis ini dengan memperbanyak sampel penelitian, dengan metode yang berbeda dan uji yang berbeda. Dan diharapkan Hasil penelitian ini berguna sebagai sumber informasi dan bahan masukan bagi Poskesdes Desa Rengas Kec. Payaraman Kab. Ogan Ilir tentang hubungan pemberian imunisasi dasar dengan perkembangan bayi usia 9 dan 12 bulan menambah wawasan mengenai pemberian imunisasi dasar dengan perkembangan bayi usia 9 dan 12 bulan tidak hanya berpatok dalam pelayanan kesehatan saja misalnya imunisasi, tetapi dari peran orang tua sendiri dalam memberikan kebutuhan bayi yang berupa Asah yaitu rangsangan atau latihan.

\section{UCAPAN TERIMA KASIH}

Penulis mengucapkan terima kasih kepada seluruh pihak yang membantu dan yang telah memberi dukungan terhadap penelitian ini.

\section{DAFTAR PUSTAKA}

Dewi, Vivian Nanny Lian. 2014. Asuhan Neonatus Bayi dan Anak Balita. Salemba Medika : Jakarta.

Depkes, 2018. Berikan Anak Imunisasi Rutin Lengkap ini Rinciannya. http://www.depkesgo.id/article/prin t/18043000011/berikan-anakimunisasi-rutin-lengkap-ini rinciannya.html (diakses pada tanggal 11 Maret 2019 Pukul 20:15 WIB).

IDAI. 2017. Jadwal Imunisasi. ukses pada tanggal 12 Maret 2019 Pukul 13:00 WIB). 
Kementrian Kesehatan.

2018 http://promkes.kemkes.go.id/?p=898 6 (di akses pada tanggal 11 Maret 2019 Pukul 06:25 WIB).

Maryunani, Anik. 2010. Ilmu Kesehatan Anak dalam Kebidanan. Trans Info Medika : Jakarta.

Media Neliti. 2016. Hubungan Pemberian Imunisasi dengan Tumbuh Kembang Bayi Usia 0-1 Tahun.https://media.neliti.com/medi a/publications/110870-ID-hubunganpemberian-imunisasi-dasardenga.pdf (di akses pada tanggal 10 Maret 2019 Pukul 22:30 WIB).

Sugiyono. 2015. Metodologi Penelitian Pendidikan. Alfabeta : Bandung.

Univeristas Hasanuddin. 2018. Buku Panduan Kuesioner PraSkrining Perkembangan (KPSP). https://med.unhas.ac.id/kedokteran/ wpcontent/uploads/2018/03/KUESI ONER-PRA-SKRINING-

PERKEMBANGAN-KPSP.pdf. (di akses pada tanggal 12 Maret 2019 Pukul 17:00 WIB).

Universitas Muhammadiyah Surakarta. BABI.http://eprints.ums.ac.id/29361/ 3/BAB_I.pdf (diakses pada tanggal 11 Maret 2019 Pukul 15:10 WIB).

Universitas Sebelas Maret. 2016. Peran Imunisasi untuk Menunjang Tumbuh Kembang Balita Anak Indonesia

Berkualitas.https://library.uns.ac.id/p eran-imunisasi-untuk-menunjangtumbuh-kembang-balita-anakindonesia-berkualitas/ (di akses pada tanggal 11 Maret 2019 Pukul 14:00 WIB).

WHO. 2015.2 Immunization. https://www.who.int/topics/immuniz ation/en/ (di akses pada tanggal 11 Maret 2019 Pukul 08:00 WIB).

WHO. 2018. Infants Worldwide Vaccination.

https://www.who.int/immunization/n ewsroom/2018_infants_worldwide_v accinations/en/ (diakses pada tanggal 11 Maret 2019 Pukul 15:40 WIB). 